UCRL-53277

Distribution Category UC-2

UCRI --53277

DE82 020454

\title{
A Look At Nuclear-Artillery Yield Options Using JANUS, A Wargame Simulation Code
}

\author{
C. G. Andre
}

Manuscript Date: June 15, 1982

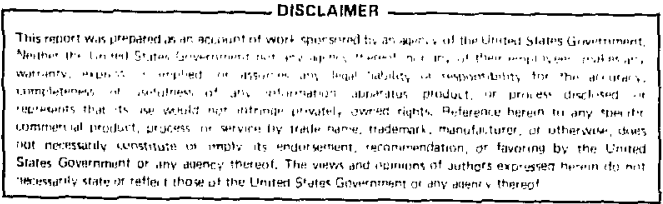

LAWRENCE LIVERMORE LABORATORY University of California * Livermore, California 94550 


\section{Contents}

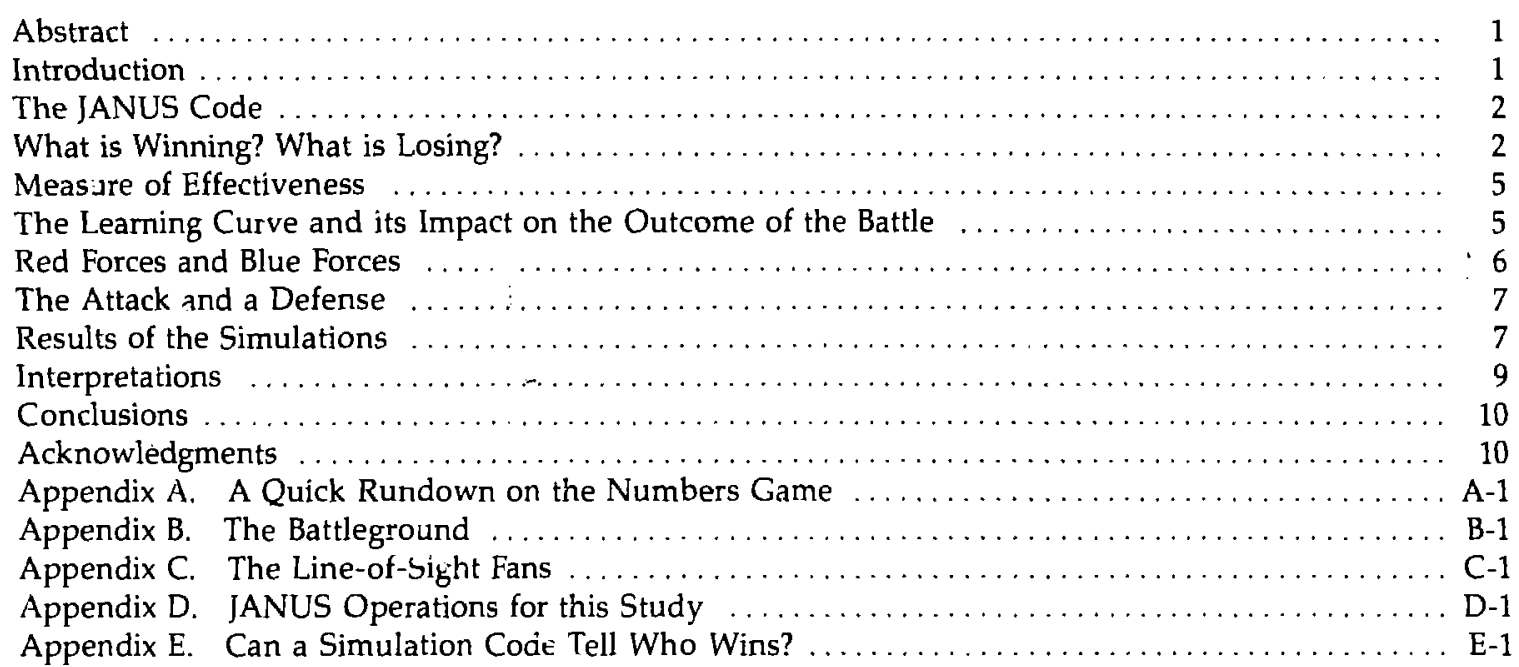




\title{
A Look At Nuclear Artillery Yield Options Using JA.NUS, A Wargame Simulation Code
}

\begin{abstract}
JANUS, a two-siajed, interactive wargame simulation code, was used to explore how using each of several different yield options in a nuclear artillery shell might affect a tactical battlefield simulation. In a general sense, the results or outcomes of these simulations support the results or outcomes of previous studies. In these simulations the Red player knew of the anticipated nuclear capability of the Blue player. Neither side experienced a decisive win over the other, and both continued fighting and experienced losses that, under most historical circumstances, would have been termed unacceptable-that is, something else would have happened (the attack would have been called off). During play, each side had only fragmentary knowledge of the remaining resources on the other side-thus each side desired to continue fighting on the basis of known information. We found that the anticipated use of nuclear weapons by either side affects the character of a game significantly and that, if the employment of nuclear weapons is to have a decided effect on the progress and outcome of a batile, each side will have to have an adequate number of nuclear weapons. In almost all the sinulations we ran using JANUS, enhanced radiation (ER) weapons were more effective than 1-kt fission weapons in imposing overall losses on Red. The typical visibility in the JANUS simulation limited each side's ability to acquire units deep into enemy territory and so the 10-kt fission weapon was not useful against enemy tanks that were not engaged in battle. (Troop safety constraints limited its use on tanks that were engaged in direct fire with the enemy.)
\end{abstract}

\section{Introduction}

JANUS, a two-sided, interactive wargame simulation code, was used to explore how using each of several different yield options in a nuclear artillery shell might affect a tactical battlefield simulation. Nominally, an enhanced radiation (ER) weapon and a $10-\mathrm{kt}$ fission weapon produce similar radiation kill effects but significantly different thermal and blast effects, anct an ER weapon and a 1-kt fission weapon produce similar thermal and blast effects.

Practically all previous studies on the use of different yield options in an artillery shell focused on a threat that was either static or dynamicdynamic only in the sense that the opposing forces moved in prescribed, predetermined manner. The details of the threst were modified or altered only in terms of attrition imposed by the employment of nuclear weapons. (The same troops were not killed twice.) Since JANUS is player resfonsive in its troop movements each player coulri adjust iactics to compensate for both nuclear and conventional losses. Whether or not these new tactics would be allowed by either U.S. or Soviet doctrine or by other battlefield constraints is unknown. Standard Soviet tactics might dictate a different, contrary configuration of forces to achieve the same objective.

In a general sense, the results or outcomes of our many different simulations support the results or outcomes of previous studies. For example, on the average, a 1-kt fission weapon nets one company of enemy tanks or BMPs. In JANUS Red can usually vary his tactics so that he will not lose more than one company to a single weapon. Without a firm, realistic, game-time schedule demand, Red can maneuver to keep his losses in 
step with those of Blue and not present a complete battalion as a suitable target. In some instances this ratio of one company lost per weapon absorbed also holds true for an ER weapon.

In our simulations Red, of course, knew of the anticipated Blue nuclear capability. Had Red gone into battle assuming that no nuclear weapon would be used against him and such a weapon was then used, he would have suffered rather significant losses due to the massing of his forces. Alternatively, had Red increased his intercompany spacings, he would have been able to cope with an anticipated nuclear attack. Red's only liability if the battle did not become nuclear was a slowing of the battle's tempo.

In almost all the simulations, neither side experienced a decisive win or loss. Both sides continued fighting and experienced losses that, under most historical circumstances, would have been termed unacceptable - that is, something else would have happened (the attack would have been called off or delayed). Also, Red frequently had a remaining numerical count (in the summing of all his disparate forces) that was regimental in size. Adroitness in reorganizing would have allowed this force to overcome the severely decimated Blue defense, particularly if there had not been any stringent battle time schedules. Thus, in one sense Red was not defeated to the point where, in the code simulations, he could not still make an objective by a later time. The game was usually terminated, however, before this reorganizing could take place. It must not be forgotten that, during play, each side had only fragmentary knowledge of the remaining resources on the other side-thus the desire of each to continue fighting on the basis of known information.

\section{The JANUS Code}

The JANUS code is described in other literature in varying detail. As used in this study, JANUS was a computer program on a standalone, dedicated Varian computer associated with a good interactive graphics capability. (Since these simulations have been run, JANUS has been modified and moved to a Vax computer.)

In our simulated wargames a series of red and blue symbols represented units of Red and Blue tanks, armored personnel carriers, artillery, helicopters, and many of the other componerits of a fighting army. One or two players on each side, and in different rooms, gave movement orders to the various units that make up the Red or the Blue forces. Red was configured as a tank division (320 tanks) challenging a defending Blue brigade (100 tanks). Red's line of sight on Blue and vice versa made limited numbers of the enemy's forces visible to each side. Conventional direct fire was completely modeled and automated in the code. The players aimed and fired nuclear rounds at their option after considering appropriate reaction time delays for the system.

\section{What is Winning? What is Losing?}

Although definitive boundaries of winning and losing are difficult to establish, there appears to be some consensus that if Blue loses a greater percentage of forces than Red, Blue is indeed losing or is in an untenable position, and something, somewhere else, will happen. For example, a higher command might intervene with other assets. On the other hand, if Blue's percentage of loss is less than Red's percentage by a factor of 0.6 , the Blue brigade is holding its own, and the attack by Red is failing.

There also seems to be a loose consensus that if Red's losses approach from 40 to $50 \%$ (or mayie
$60 \%$ ), Red will rethink the situation and not continue the offensive. But, Red may reorganize and attack again.

Both of these criteria are shown in Fig. 1. The top half of the figure illustrates the first situation. giving the upper limit on Blue's losses as a fraction of Red's losses. The region between the two lines is the locus of game history points that differentiates between Blue winning only the battle and Blue winuing both the battle and the war. The lower diagram serves to illustrate that Red's losses alone, once they exceed 40,50 , or $60 \%$, are sufficient to call the battle or war a Blue success. 

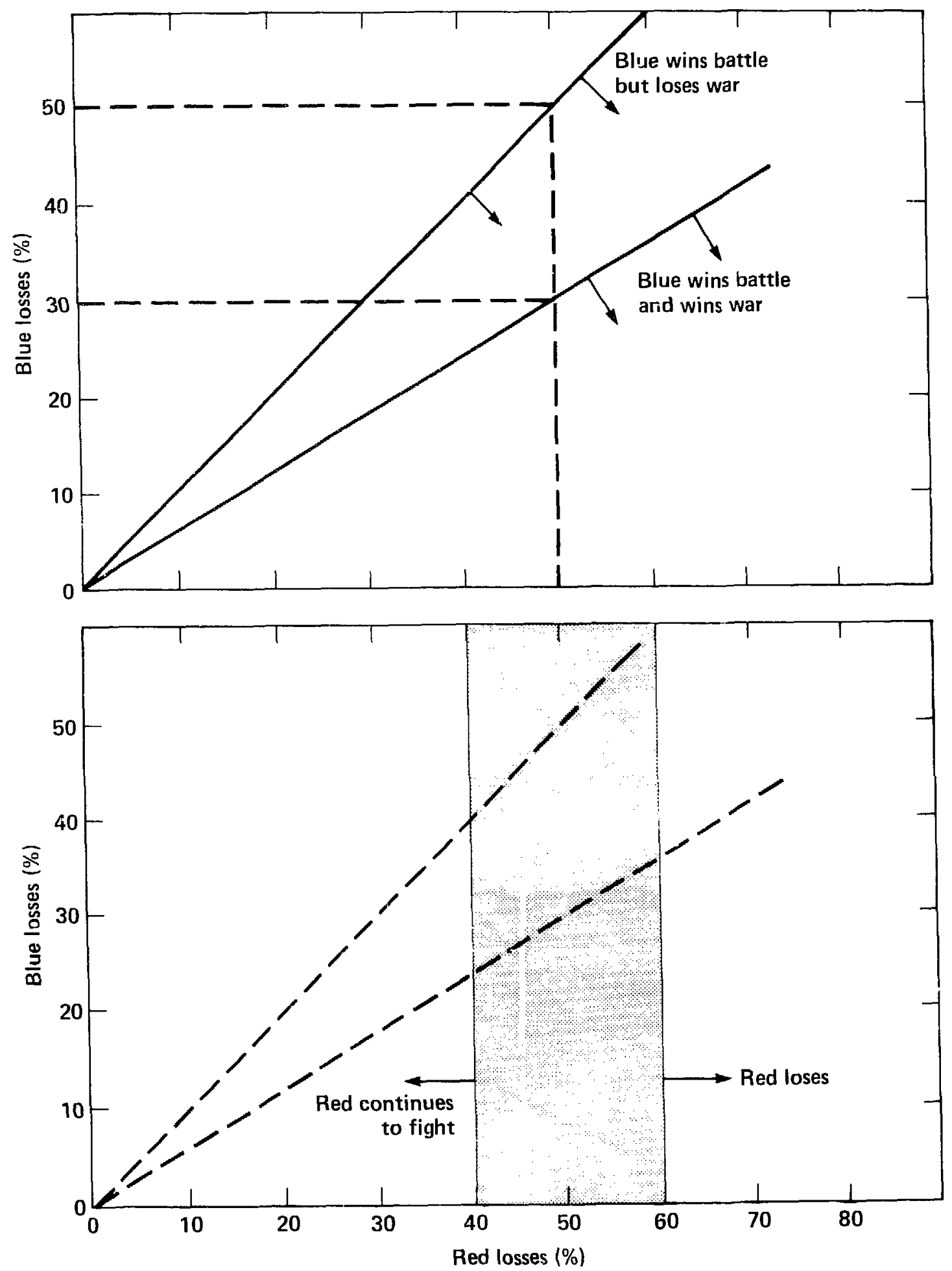

Figure 1. Boundaries for winning and losing. The upper half of the figure illustrates two situations: (1) Blue's Iosses are greater than Red's sr: he is losing to Red and (2) Blue's losses are less than Red's so he is holding his own and the aitack by Red is failing. The lower half of the figure illustrates that once Red's losses exceed 40,50 , or $60 \%$ they are sufficient to call the battle or the war a Blue success. 

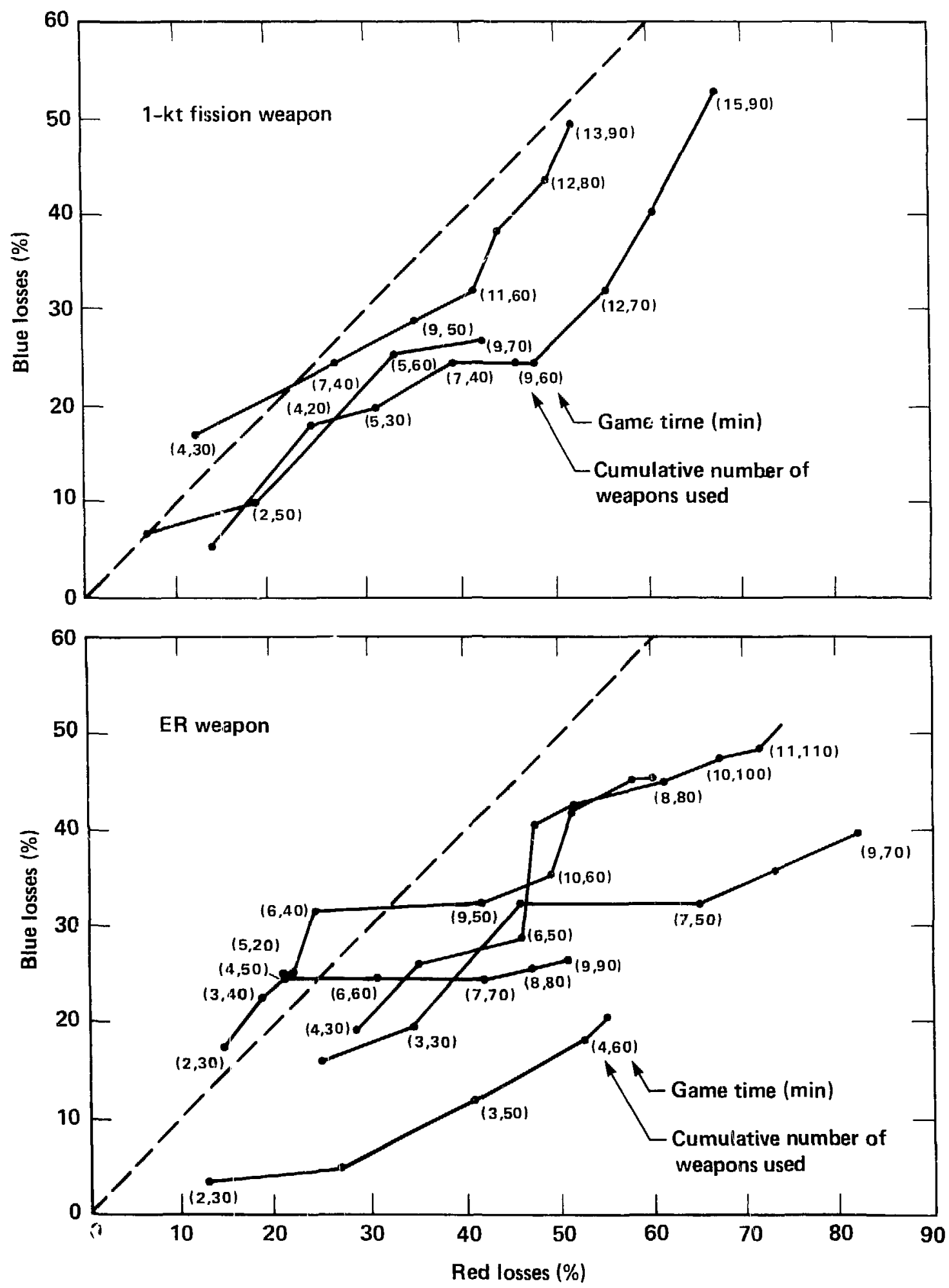

Figure 2. The percentage of Blue's lusses compared with the percentage of Red's losses. The upper half of the figure shows the results for a number of games in which Blue primarily used 1-kt fission weapons against a Red attack. The lower half shows the results of games in which Blue used ER weanons. In general, the battles worked better for Blue when he could use an ER weapon. 


\section{Measure of Effectiveness}

As is frequently the case in any study, defining a reasonable measure of effectiveness is difficult. This problem is even more severe in a simulation code game, where many variables are chosen at the player's option, depending on the course of play.

Furthermore, the measure of effectiveness is evaluated after the game has been called complete. The completion of each game is the result of some value judgment exercised by either player or by some third party, and is not necessarily based on the measure(s) of effectiveness selected for analysis.

One measure of effectiveness we used to compare the different sets of simulations was the percentage loss of Blue forces versus the percentage loss of Red forces as the battle progressed. Figure 2, a battle-history summary, shows this. The losses of tanks plus TOW's for Blue (or tanks and BMPs for Red) were chosen to represent losses of combat strength.

Another measure of effectiveness that possibly could have been used is the rate of the Red advance, which determines whether or not the at- tack objective is accomplished in a timely manner. The timely accomplishment of an objective is inherent and explicitly stated in much of Red's doctrine. Red's dispersion to avoid nuclear weapon effects would presumably cause delays in his timetable. But, it is difficult to set a hard and fast time for achieving a specific objective.

We wished to compare the delays caused by the ER weapon with those caused by the 1-kt fission weapon. However, because of deficiencies in the code's treatment of off-road velocities, we were unable to develop a "reasonable" battle time scale to make these comparisons. Even after correcting these deficiencies, we could not correlate the times of the simulations run before and after because we did not have sufficient resources of time and manpower to redo the earlier simulations with the more adequate off-road velocities. (The points plotted in Fig. 2, which compares the percentage of Blue's losses with the percentage of Red's, are labeled with the times at which the data were logged. Almost all points indicate very large attrition rates-that is, a very large loss in a relatively short time.)

\section{The Learning Curve and its Impact on the Outcome of the Battle}

We have found that the results of the first several simulations are only useful in establishing plausible conclusions if a player is experienced. If a player is inexperienced, i.e., if he lacks full knowledge of each symbol on the screen, the entity it represents, the portion of it that identifies a centroid position for each item it represents, and the interaction of the unrepresented positions with the terrain, the outcome of the simulation will depend on the player's ability to learn these features rather than on a measure of the effectiveness of some weapon parameter. Another liability of the inexperienced player is that he must focus his attention on manipulating screen symbols and the cursor. The experienced player, however, may focus his attention on viewing actions on the screen and developing tactics.

To be played well, the game and its idiosyncrasies have to be learned. Thus, past experience is not only readily evident in actual playing but in setting up a defense or in forging an offensive. In both cases, setting up a defense and torging an offense, a detailed knowledge of the terrain, and the positioning of forces advantageously within it, is of great importance. Since JANUS is limited in topographical resolution, the rolling surfaces it uses as obstructions to lines of sight are not readily derived from studying a map. The code's terrain has to be learned independently, which, in most cases, is done through extensive play. With the aid of the line-of-sight display, one can reposition units to improve ufon an original configuration. Past experience is also beneficial in developing tactics to marshal all the game's forces for the best offense or the best defense.

These factors--the familiarity with the symbols, a detailed knowledge of the code's terrain, and the development of tactics that are in keeping with the JANUS algorithms-influence the outcome of the game. Changing internal parameters (usually by improving data or correcting the code) can produce excursions in the outcome of the next games played not unlike those produced by a new player as he becomes conditioned. Some of these changes become less significant as more games are played and players compensate for them. For other changes, the series of games takes on another norm. 


\section{Red Forces and Blue Forces}

The Red forces attacking Blue's positions were a reinforced tank division consisting of 319 tanks, 186 BMPs, and numerous other assets, such as helicopters, artillery, observers, and engineering units. A complete listing of the items is given in Table 1. A Red division was subdivided into about four regiments, each consisting of about three battalions of three companies. A company consisted of about 10 units, either tanks or BMPs. In all, about 50 companies opposed Blue.

In the simulations the players frequently used two of the regiments in an attempt to develop the main attack in a locale measuring 4-6 km wide. One regiment kept Blue tied up at another locale while the other stayed back to help the first two regiments achieve the objective. Helicopters, ob- servers, and artillery augmented the Red fighting units.

Blue forces were severely outnumbered by the total Red forces. Blue attempted to hold off the attacking Red division with a brigade consisting of 102 tanks, 24 TOWs, and 18 dragons (shortrange- $1.5 \mathrm{~km}$-guided munitions), plus helicopters, mortars, artillery, etc. A detailed listing of Blue's assets is given in Table 1 . The number of Blue forces and the total area defended in the computer simulation were not unlike the number of Blue forces and total area defended in an actual wargame in West Germany. Red outnumbers Blue by a ratio of over $3: 1$ in tanks and by a ratio of over $4: 1$ in units with anti-tank guided munitions.

Table 1. Detailed listing of Red forces and Blue forces.

\begin{tabular}{|c|c|c|c|c|}
\hline \multirow[b]{2}{*}{ Tanks } & \multicolumn{2}{|c|}{ Red } & \multicolumn{2}{|c|}{ Blue } \\
\hline & T-62 & 319 & M-60 & 102 \\
\hline Armored personnel carriers & BMP & 186 & TOW & 24 \\
\hline Armored personnel carriers with ATGM $^{2}$ & & & Dragon & 18 \\
\hline \multirow[t]{3}{*}{ Artillery } & $122 \mathrm{~mm}$ & 72 & $M 109^{b}$ & 18 \\
\hline & $130 \mathrm{~mm}$ & 36 & M110 & 4 \\
\hline & & & Mortar $^{d}$ & 12 \\
\hline Helicopters & HIND & 9 & Cobra & 10 \\
\hline \multirow[t]{2}{*}{ Anti-air } & ZSU-23 & 16 & Stinger & 15 \\
\hline & & & Vulcan & 4 \\
\hline \multirow[t]{2}{*}{ Missiles } & Frog & 4 & Lance & 4 \\
\hline & Scud & 2 & & \\
\hline Observers & BRDM $^{e}$ & 16 & $O P^{f}$ & 10 \\
\hline \multirow[t]{2}{*}{ Engineering assets } & AVLB $^{B}$ & 12 & AYLB & 4 \\
\hline & $\mathrm{CEV}^{\mathrm{h}}$ & 12 & & \\
\hline
\end{tabular}

ATGM - Anti-tank guided missile. BMP and TOW missiles have a $3 \mathrm{~km}$-range; Dragons have a $1.5-\mathrm{km}$ range.

b A 155-mm M109.

'An 8-iri. M110.

${ }^{\mathrm{d}}$ A 4.2-in. Mortar.

'With iasr-witeeled vehicles.

On foot.

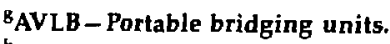

${ }^{h} \mathrm{CEV}$ - Combat engineer units. Blue has an initial setup capability consisting of $6 \mathrm{~km}$ of minefields, $1 \mathrm{~km}$ of ditches, 5 abatis (i.e., felled trees or road blecks) and 10 craters. These numbers represent Blue's capability after a presumed covering force operation has occurred and he has $16 \mathrm{~h}$ of engineering preparations by two companies. 


\section{The Attack and a Defense}

Many elements of battle-such as surprise, maneuver, and massing-may come into play in a game. As an example, let us consider massing, bringing together sufficient forces in a given locale to improve one's position with respect to that of one's opponent.

With massing, both sides choose assets from a limited or finite source to achieve an advantage at a given time. Each side must choose judiciously since its choice depends not only on an assessment of its own resources but on an estimate of its opponent's resources as well. In the JANUS games the choice is based on each side's estimate of its opponent's intent to use a nuclear round. In the absence of a nuclear exchange the attacker resorts to extensive massing to overcome his opporent, who has to maintain some kind of defensive posture along the whole front. The resultant massing frequently leaves the defender little choice but to use a nuclear round. This choice has a high payoff since many enemy companies can be killed by a single round. If the attacker anticipates a nuclear exchange, he will usually not mass as extensively as he had otherwise planned so that his opponent will not be able to eradicate a battalion or more with a single nuclear weapon.
Before the battle begins, however, the defender must anticipate the circumstances of the attack and choose his positions accordingly. The choices the defender makes are not easily altered in a game once the game has begun, because only the original positions are in defilade, i.e., pre-dug and arranged for low visibility and protection by the surroundings.

A defense in depth, which Blue is inclined to institute if he anticipates a Red nuclear attack, leaves him weaker than would a denser line or area of defense. In turn, a defense in depth will more likely cause Blue to use nuclear weapons since Red will be able to penetrate the defense more easily.

The ability to change options from game to game in the JANUS simulations belies reality because, in a real-world situation, Red could not possibly change his tactiss without training his troops extensively. This is not to imply, however, that his battle plan could not include a variety of tactics that differ from division to division, for which Blue must be prepared.

\section{Results of the Simulations}

Red was free to use up to six missiles with a $10-k t$ fission yield on each. He was allowed to fire any or all of these in the first minute of a game. A 15 -min delay time between acquisition and firing was imposed on those missiles he did not use initially. Red could hardly ever use a $10-k t$ weapon against a Blue tank platoon because he would endanger the his own troops that were in combat with the acquired Blue tank platoon. Occasionally Red used his 10-kt nuclear capability in a terrain fire mode or against Blue artillery. In any event, Blue troops were usually so dispersed that generally a Red $10-\mathrm{kt}$ weapon did little to affect the outcome of a game.

The results of a series of simulations that we have run are shown in Figs. 2-4. (Even though groups of runs are plotted in the same figure, one should not assume that all parameters in the code are common for all games shown in that one figure. JANUS was being corrected and updated extensively during the course of the study.)
The upper half of Fig. 2 shows the results for a number of games in which Blue primarily used 1-kt fission weapons against a Red attack. Red knew that Blue did not have an ER capability in these instances. (This gave Red the option of closer intercompany spacing and the opportunity for greater massing.) The points on each line are labeled with two numbers in parenthesis, the first being the number of weapons used up to that time in the game and the second being the time at which the report was taken.

The lower half of Fig. 2 shows the results of using the ER weapons. In general, the battles worked better for Blue when he could use an ER weapon. The troop safety constraints for the ER weapon vs the 1-kt fission weapon (both of which kill principally by radiation) did not hinder aimpoint selection much. Frequently the extended lethal area of the ER gave Blue a bonus if Red did not work diligently at maintaining sufficiently large intercompany sparing. 


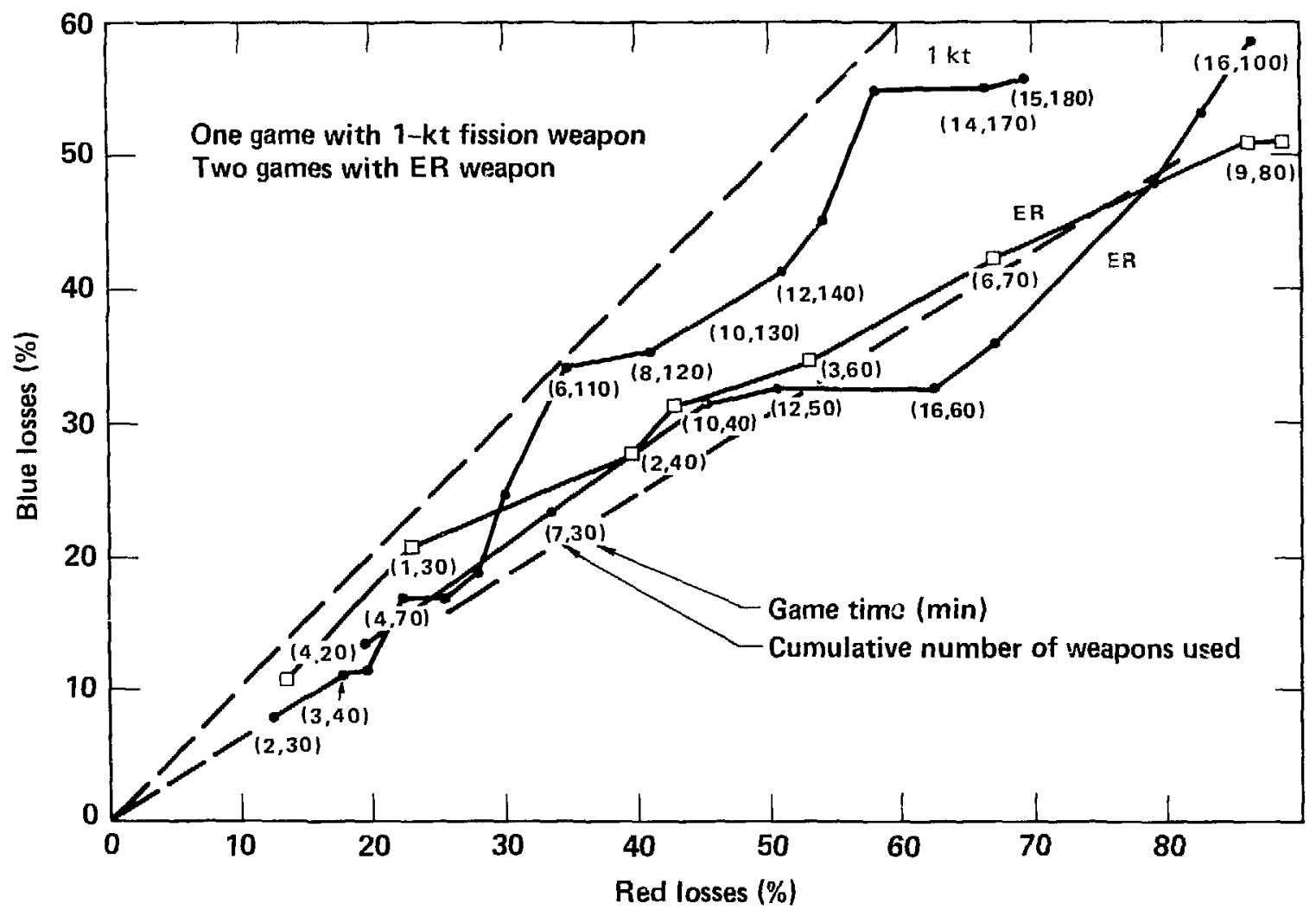

Figure 3. The results of one 1-kt game and two ER games played after the JANUS off-road vehicle velocity algorithm had been corrected. The interpretations we offered previously for the 1-kt vs ER games also hold true for this set of games. However, this set of games lasted longer than the other 1-kt vs ER games because the Red forces moved more slowly.

Figure 3 shows the results of three simulations we ran after the JANUS off-road vehicle velocity algorithm had been corrected. One run is with 1-kt fission weapons; the other two are with ER weapons. The trends shown in Fig. 1 hold here as well. Since the difference that occurred in play was that battle time proceeded more quickly than movements on the screen, troops temporarily incapacitated for $1 \mathrm{~h}$ were able to start functioning again. If one were to hold fast to the logic that Red needs a relatively rapid advance to meet his objective, the use of even the $1 \mathrm{kt}$ fission weapon, though not necessarily convincing on a ratio-oflosses basis, is successful in terms of delay and overall Red attrition.

The data collected in the simulations can also be interpreted in another way. We can examine the number of units in which the troops become casualties ( $8000 \mathrm{rad})$ as a function of the number of nuclear weapons employed. The results for a 1-kt fission weapon vs those for an ER weapon are shown in Fig. 4. The results of several runs are consistent in the case of the 1-kt fission yield since usually one company is lost per weapon employed. In the simulations run with the ER weapon, some Red players did not keep intercompany spacing large enough to force Blue into a "one company only per weapon used" situation. Thus, in cases where Red allowed close spacing, Blue could reap additional benefits.

In Fig. 4, the point at which Red experienced an overall loss of $50 \%$ shows that Blue frequently used more 1-kt weapons than ER weapons. 


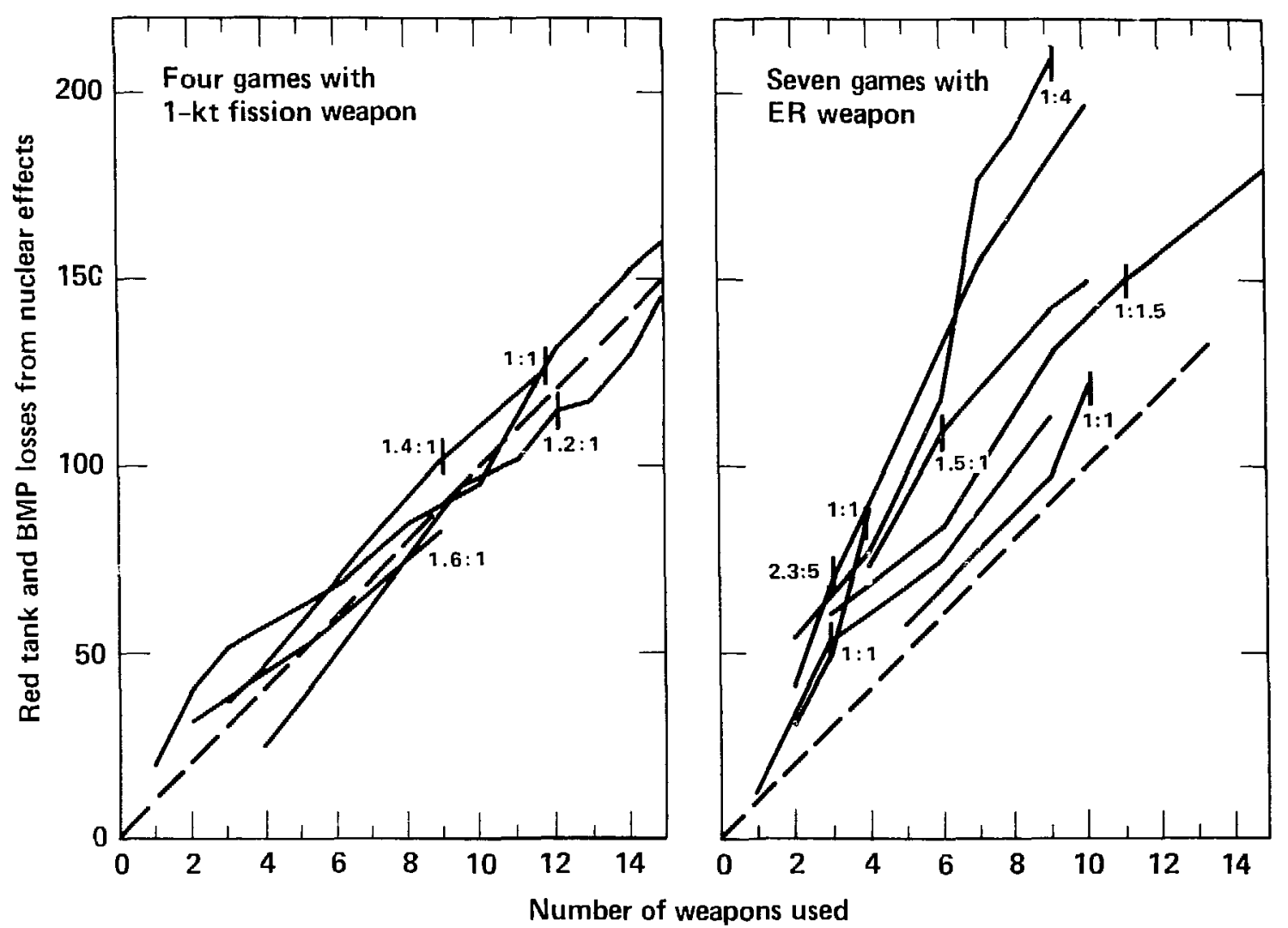

Figure 4. Results of a 1-kt game vs results of an ER game. A vertical line shows when Red conventional plus nuclear losses reached $50 \%$. The ratio indicated is that of conventional casualties to nuclear casualties.

\section{Interpretations}

A comparison of the loss histories of the $1-\mathrm{kt}$ games vs the ER games (Fig. 2, top vs bottom) shows, in general, that the ER weapon is more effective than the 1-kt weapon. Practically all the ER game histories proceed directly toward a Blue victory, regardless of whether the measure of effectiveness is the ratio of Blue to Red losses or the absolute loss of Red forces. The 1-kt games show a good history for Blue while there is an adequate supply of weapons. Once Blue has used about 10 weapons, the trend begins to favor Red since Blue is saving his last few for anticipated situations later on. However, during the time Blue is using lus 1 -kt fission weapons, he is holding his own well and forcing Red to a loss of at least $40 \%$.

In many instances during a game Blue was forced into an unacceptable region of the loss ratio graph until he used his nuclear weapors. The inference is that if no nuclear weapons had been used Red would have won these battles. (Be careful not to infer that Red would win consistently if no nuclear weapons were used. Blue could defeat Red without nuclear weapons if a small enough "localized" objective were stated for Red because Blue could then mass appropriately for a defense.)

Figure 3 plots the results of one 1-kt game and two ER games played after the off-road velocity algorithm for BMPs was corrected. The interpretations we offered previously for the 1-kt vs ER games also hold true for this set of games. However, this set of games lasted longer than the other 1-kt vs ER games because the Red forces moved more slowly. Thus, the 1-kt game in this set could be called a Blue win because Blue pushed Red's losses to exceed $40 \%$ and delayed Red muich longer than usual. Game time was $180 \mathrm{~min}$ for this $1-\mathrm{kt}$ game and about $90 \mathrm{~min}$ for the other two. 


\section{Conclusions}

1. The anticipated use of nuclear weapons by either side affects the character of a game significantly. It determines how Blue will plan his defense and how Red will carry out his offense. It causes both sides to keep large spacings between companies (or platoons), slowing the tempo of the battle.

?. If the employment of nuclear weapons is to have a decided effect on the progress and outcome of a battle, each side will have to have an adequate number of nuclear weapons. Without an adequate number, the advantage of a nuclear capability is only temporary. On the average, each side can only count on destroying one combat company per nuclear weapon used, whether it is a 1-kt fission weapon or an ER weapon. Since the enemy has 50 combat companies per division, each nuclear weapon can only destroy $2 \%$ of a division. Even after using 10 nuclear weapons, Blue fails to blunt the overall Red capability.
3. In almost all the simulations we ran using JANUS, ER weapons were more effective than $1-k t$ fission weapons in imposing overall losses on Red. Essentially all the geme histories illustrate this. This does not necessarily mean that more Red units were killed per ER veapon ur ad (which, of course, can be the case) but that the ER weapon causes a greater dispersion of Red forces, helping Blue's conventional capability. Thus, force massing can be more of a liasility with ER weapons than with 1-kt fission weapons.

4. The typical visibility in the JANUS simulation limits either side's ability to acquire units deep into enemy territory. Thus, neither side had many opportunities to use a 10 -kt fission weapon against deep enemy positions. Troop safety constraints limited use of the $10-\mathrm{kt}$ fission weapon between companies that could see each other in direct-fire combat.

\section{Acknowledgments}

A two-sided simulation such as JANUS needs at least two people to carry out a single game. We thank the Liverm Jre Field Command Office of DNA for supplying players for the many simulations we carried out. We are particularly grateful to Lieutenant Colonel Ted M. Kobayashi and Major Steve G. Barbee for being both players and critic. 


\section{Appendix A. A Quick Rundown on the Numbers Game}

Red has 500 units, i.e., 50 companies. Bliue wants to destroy a sizeable fraction of these. How does Blue do it?

\section{With TOWs?}

Blue has 24 TOW units with 11 rounds each, or 264 rounds in all. Discounting Blue's losses in fighting, discounting the location of defensive positions not in the attack corridor, and assuming $100 \%$ kill efficiencies, the TOW units could, at best, destroy about half of Red's units.

\section{Plus Helicopters?}

Blue has 10 helicopters with 8 rounds each. The tradeoff is that he uses 1 helicopter to kill about half of a company or that he uses 10 helicopters to kill a total of 5 companies-not a big impact. Furthermore, these longer rangé TOW units could be used more effectively against Red's helicopters.

\section{With Nuclear Weapors?}

If Biue uses nuclear weapons, he can destroy about one company per weapon. If we limit the number of nuclear weapons Blue can use, to about 10 per attacking division, he can destroy about $20 \%$ of Red's combat units.

Thus, to turn the tide of $k$ attle in his favor, Blue will have to utilize his tanks very effectively, aud, indeed, that is what usually occurs.

\section{With Tanks?}

In general, Blue's tanks, initially equipped with 63 rounds each, do not run out of ammunition, and the battle progress focuses on Blue's use of tanks, augmenter by his use of TOWs. This is not to imply that artillery could not help Elue. Frequently, however, artillery uppeared to be a greater asset for Red because he had a larger number of artillery batteries than Blue and hecause Blue did not wish to move those forces attacked to evade the effects of enemy artillery. If Blue did muve those forces, even slightly, he would lose the protection of being in defilade.* Defilade protection against attacking Red combat companies was almost a necessary mode for Blue.

-There were no alternative defilade positions in the JANUS code. 


\section{Appendix B. The Battleground}

The battleground in the JANUS simulations was a $15-\times 15-\mathrm{km}$ area in the center of a $40-\times 40-\mathrm{km}$ region in West Germany bordering on East Germany. A Blue brigade was defending a 12-km line of front, protecting Bad Hersfeld and the Fulda River. Figure B1 is a reduced black and white print of a typical 1:50,000 $\mathrm{\Lambda}$ rmy colored topographical map showing the $15-\times 15-\mathrm{km}$ area. Figure $B 2$ is the same map as it is seen on the computer screen during play.

After the series of simulations was finished, one of the programmers developed a linear perspective of the $15-\times 15-\mathrm{km}$ area (Fig. B3) showing the terrain over which the battle takes place. If a player could ocrasionally get different views of the terrain during the setup and play, he would have a more direct use of subtle terrain features in his defensive posture and activity.

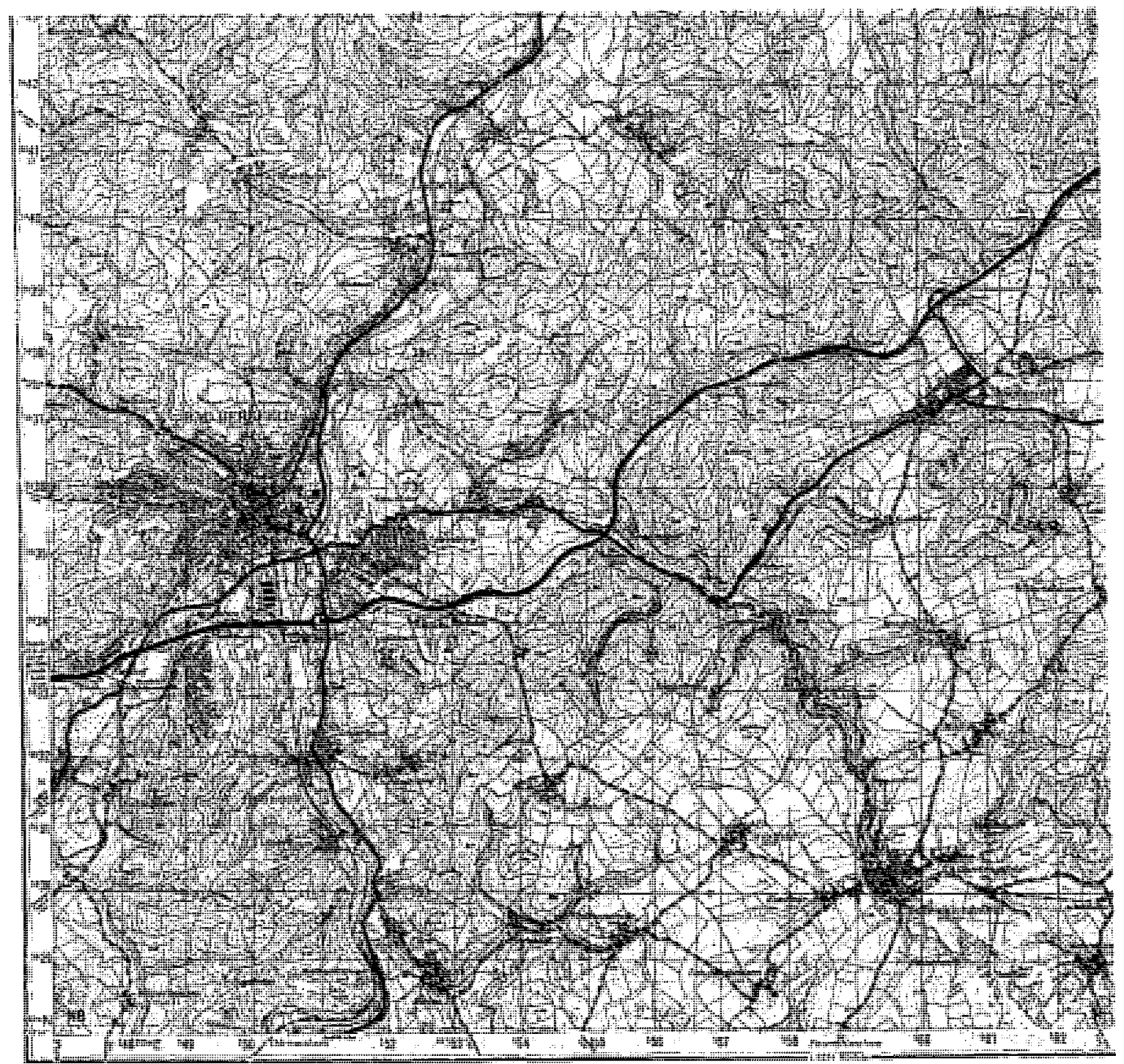

Figure B1. Army topographical map showing the 15- $\times 15-\mathrm{km}$ battleground. 
Figure B4 shows three avenues of approach that Red frequently used for his attacks. Red could obviously choose to develop his main attack in a variety of ways.

Figure B5 shows several regions of high ground that Blue often used for positioning his forces in defilade. The horizontal double line in the figure marks an agreed upon barrier designating the upper edge of the territory (12-km above the lower edge of the map) that a particular Blue brigade was defending. Other Red divisions and Blue brigades would be doing the attacking and defending to the north of this boundary.

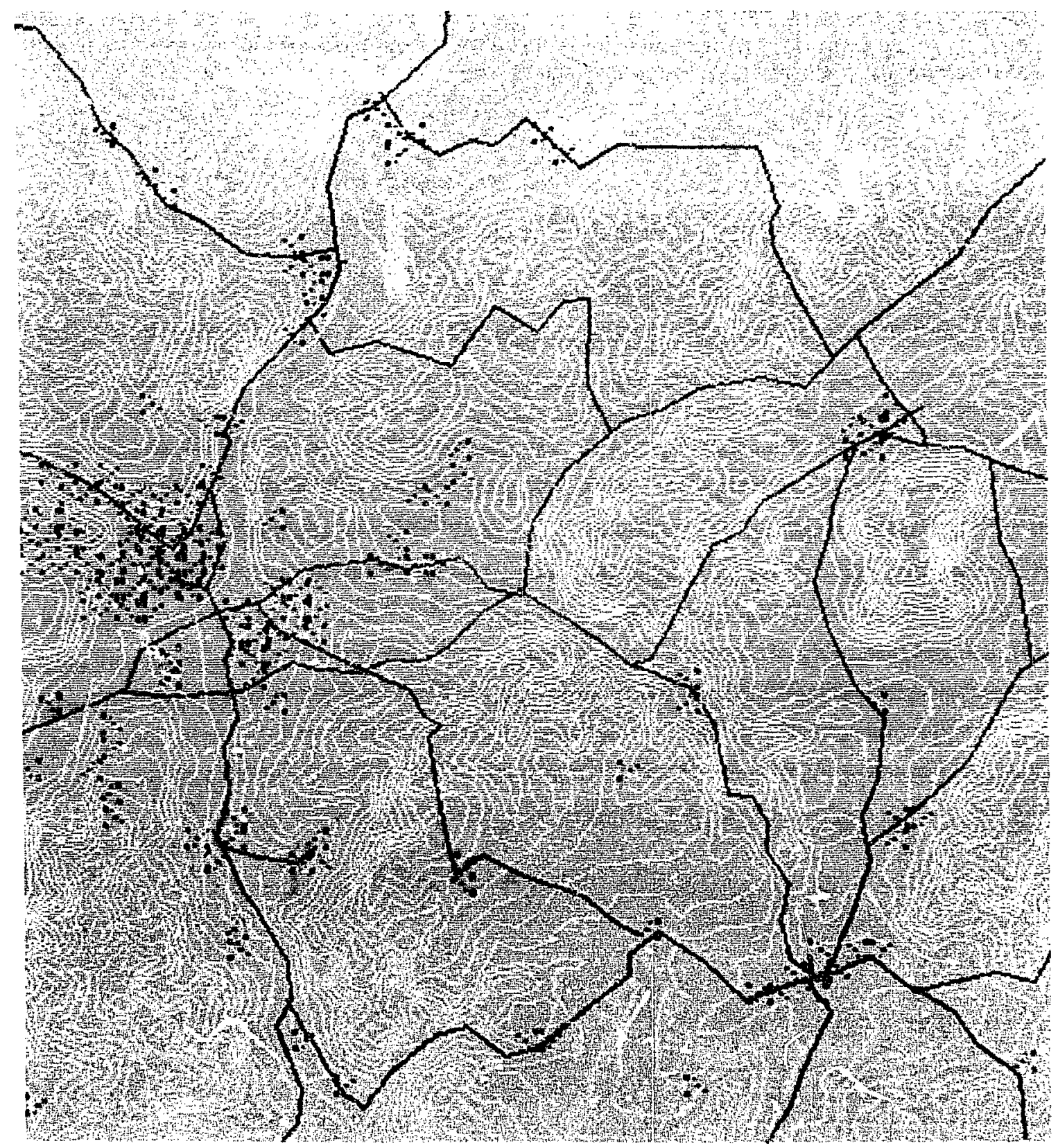

Figure B2. Army topographical map as it appears on the computer screen during play. 


\section{BAD HERSFELD (15X15)}

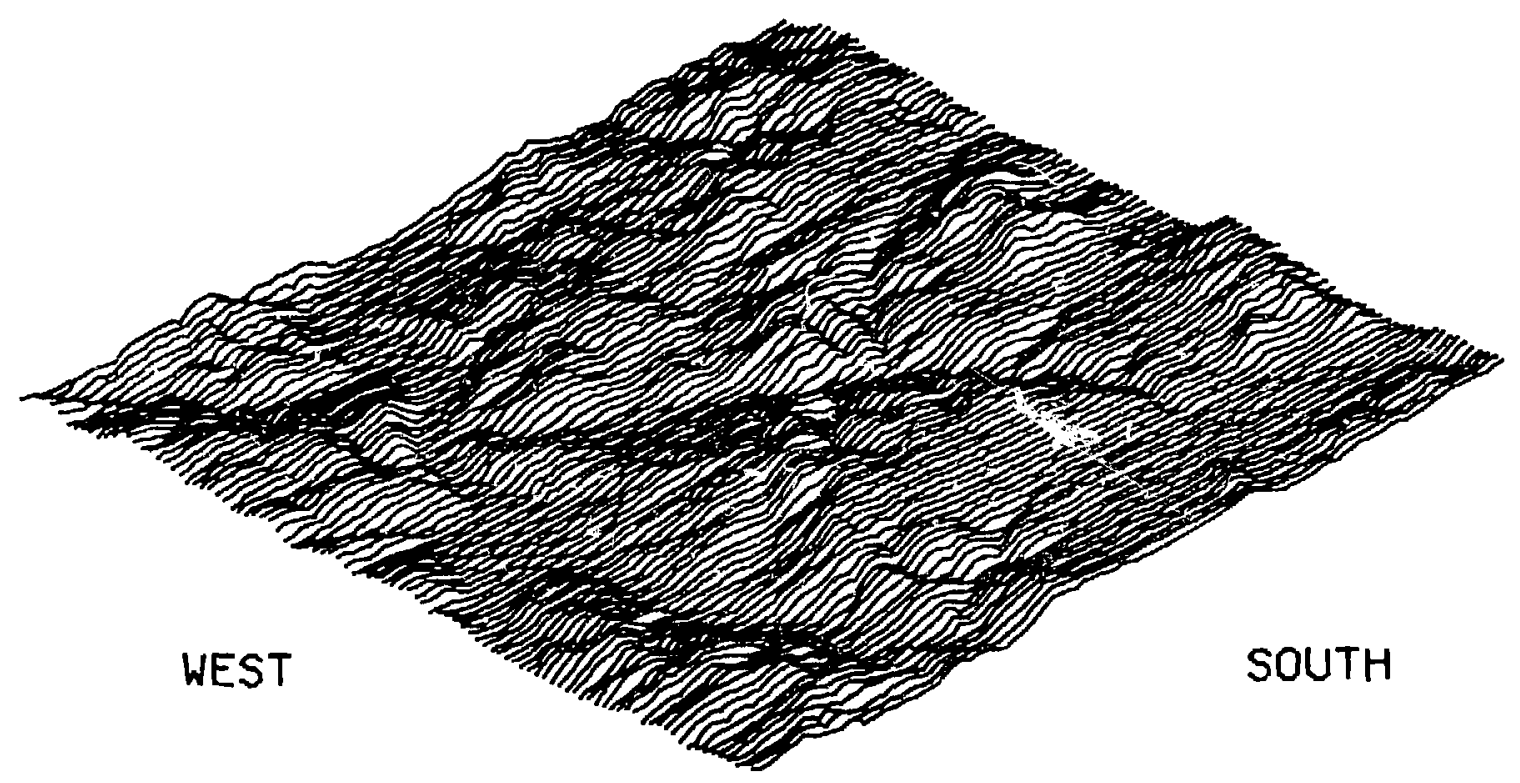

Figure B3. Linear perspective of the $15-\times 15-\mathrm{km}$ battleground showing the terrain over which the battle takes place. 


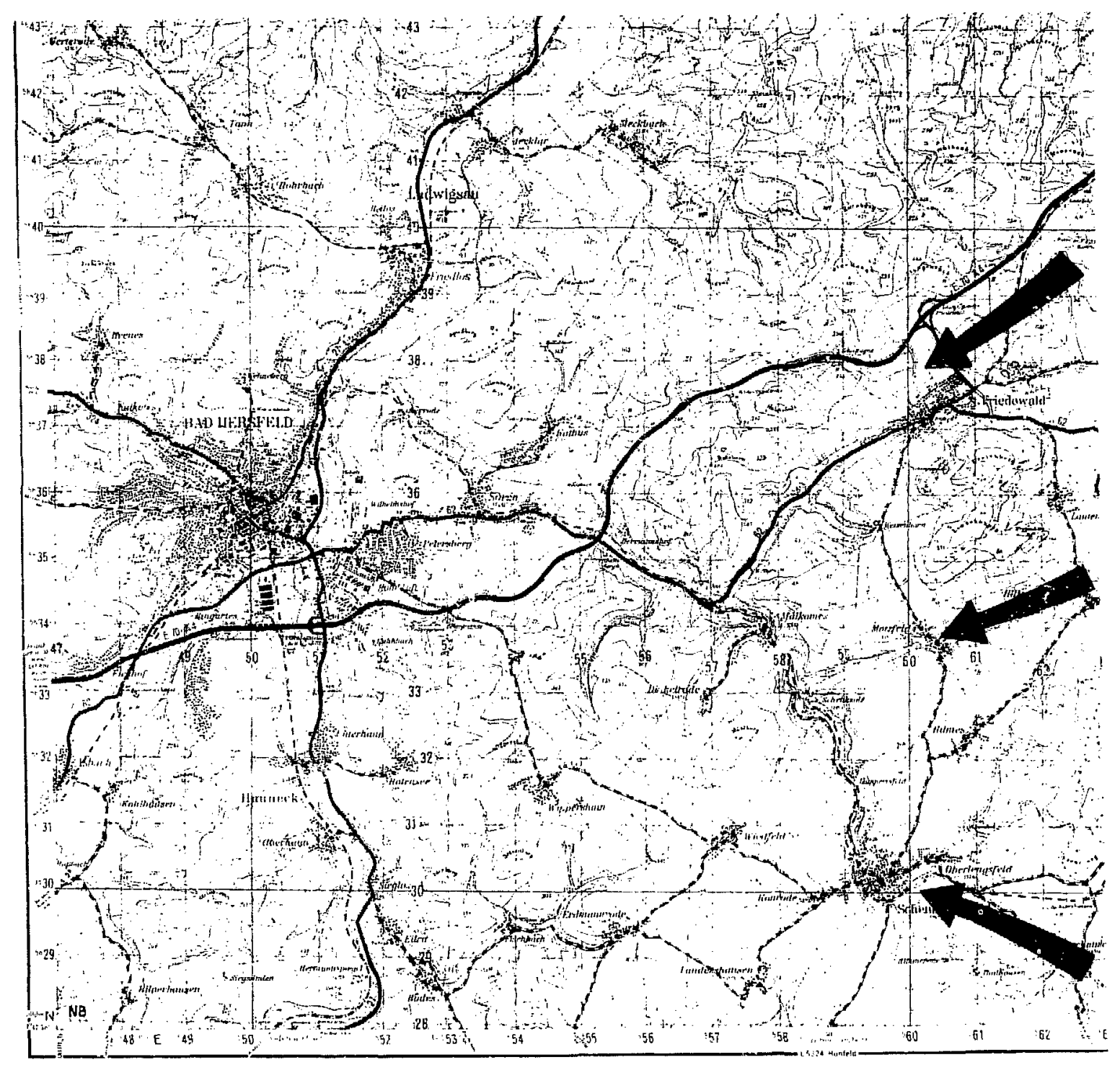

Figure B4. Three avenues of approach that Red frequently used for his attacks. 


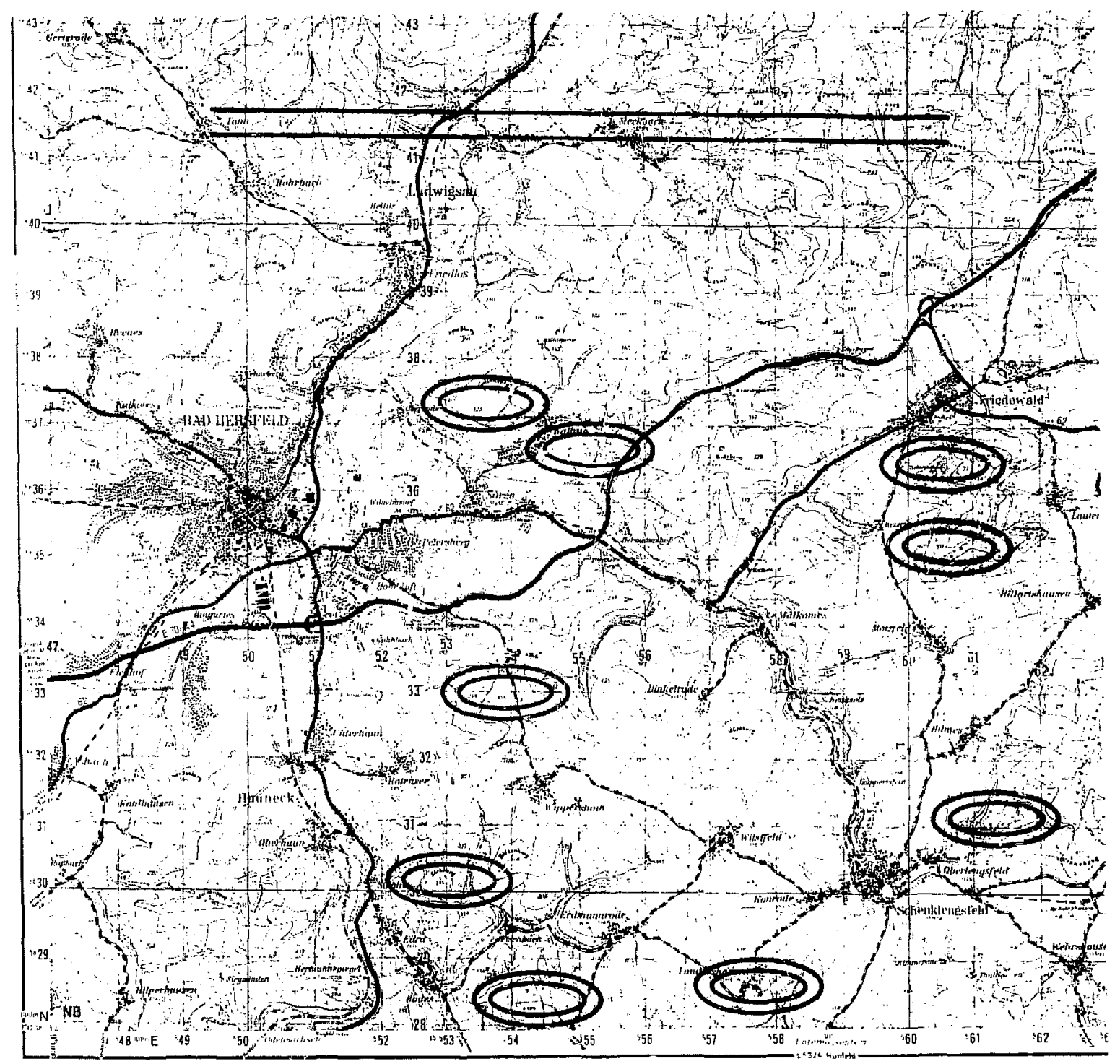

Figure B5. Regions of high ground that Blue often used for positioning his forces in defilade. The horizontal double line marks an agreed upon barries designating the upper edge of the territory that a particular Blue brigade was defending. 


\section{Appendix C. The Line-of-Sight Fans}

The line-of-sight fan for each unit (i.e., the area visible to each unit) was incorporated into JANUS to help plan for the placement of the unit. This feature was used primarily to establish Blue's best defensive positions.

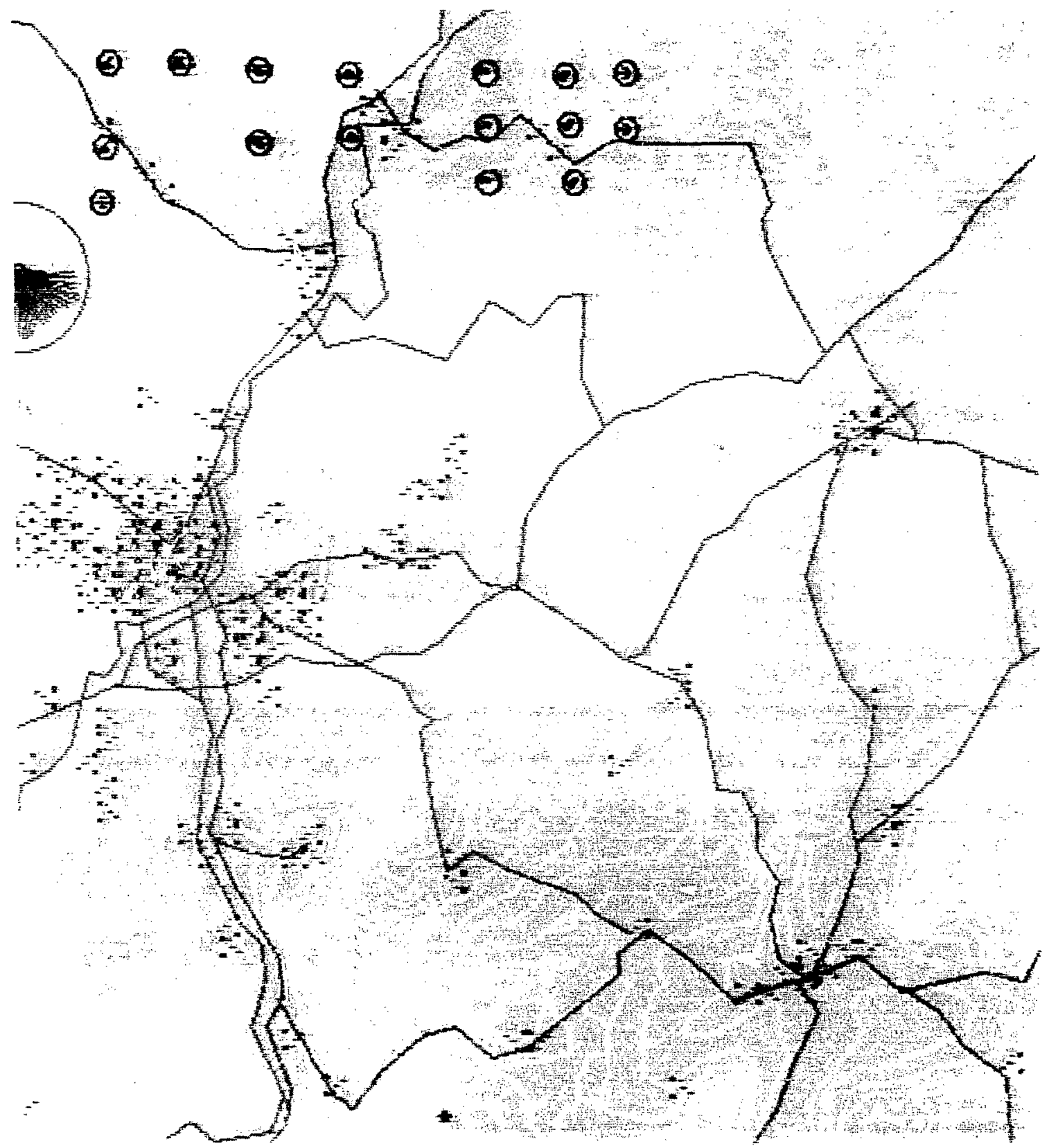

Figure C1. Typical line-of-sight fan showing location A. 
Figures $\mathrm{C} 1-\mathrm{C} 6$ show typical line-of-sight fans reaching out to the limit of visibility, which was most often $6.3 \mathrm{~km}$.* It iese figures also show the variations in the extent of line-of-sight visibility from slightly different ground locations. Figures $\mathrm{C} 1, \mathrm{C} 3$, and $\mathrm{C} 5$ show the specific locations and Figs. $\mathrm{C} 2, \mathrm{C} 4$, and $\mathrm{C} 6$ the lines of sight fo, those locations. The centroid of the symbol is the point of interest. A line of sight changes dramatically for a slight change in location if one is near a crest.

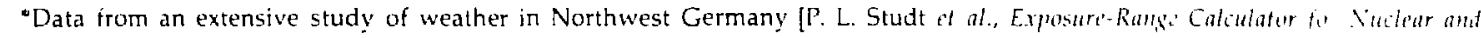
Thermal Radation, M-072 : April 13, 1976) (title (U, report SRD)] show that there will be a visibility of $6.3 \mathrm{~km} 50 \%$ of the time.

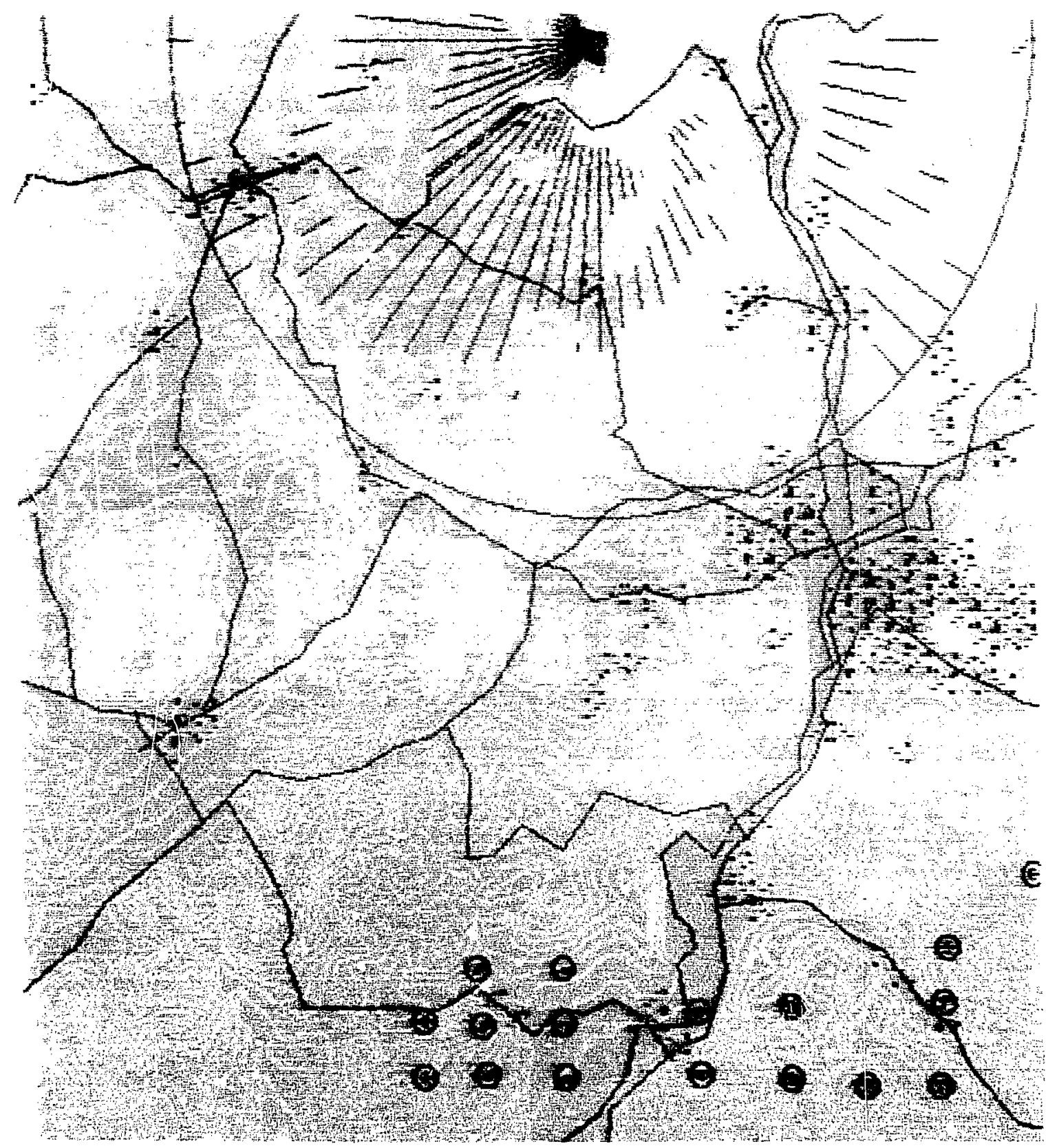

Figure C2. Typical line-of-cight fan showing line of sight for location A. 
The line-of-sight lines represent the ground locations at which a tank is visible. Thev do not show the more limited area where the ground itself is visible. The line-of-sight display does not indicate the decreased vicibility that troops experience in forests. That phenomenon was modeled stochastically in the cole once there was a line of sight for such a ground location.

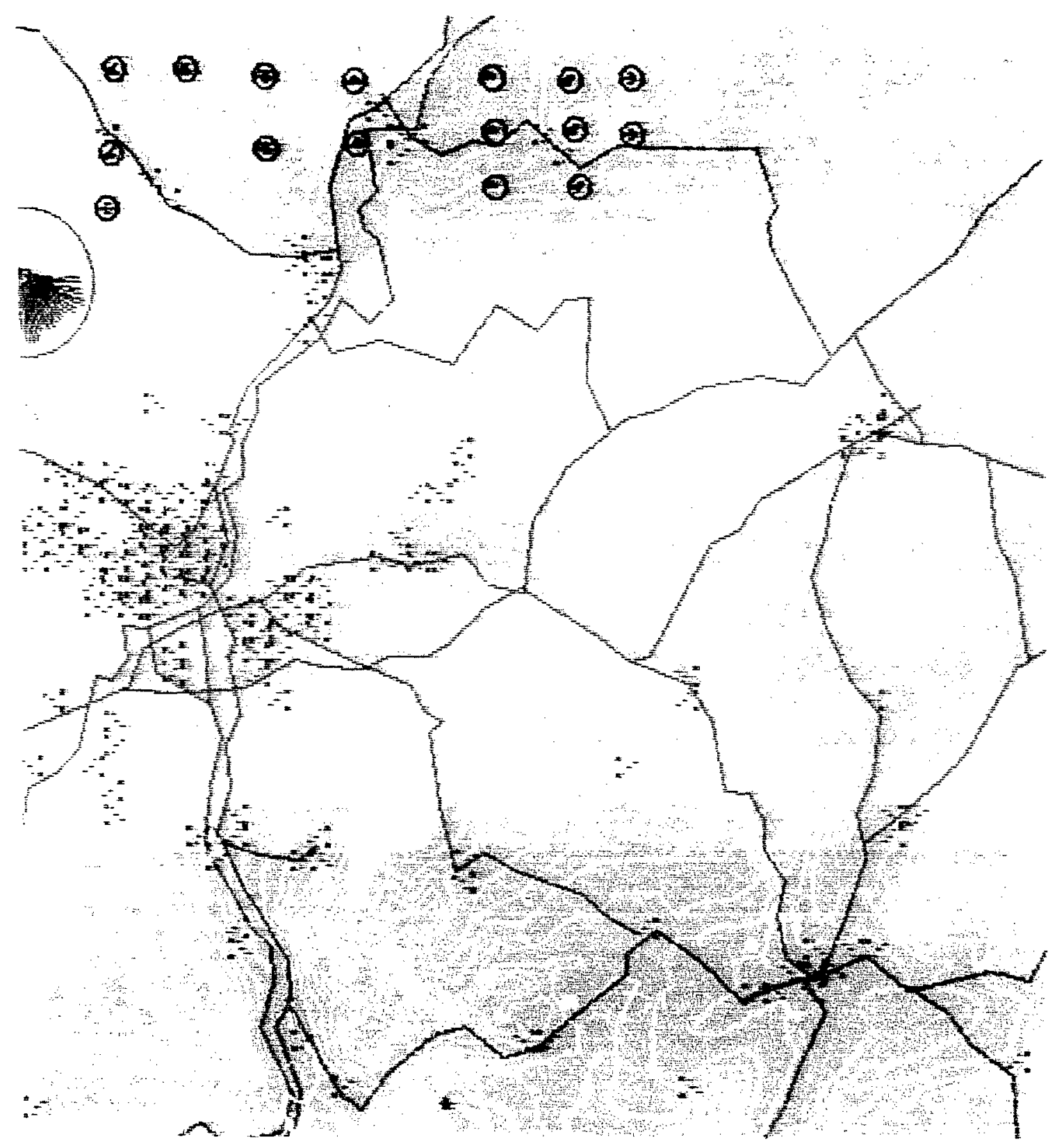

Figure C3. Typical line-of-sight fan showing location B. 


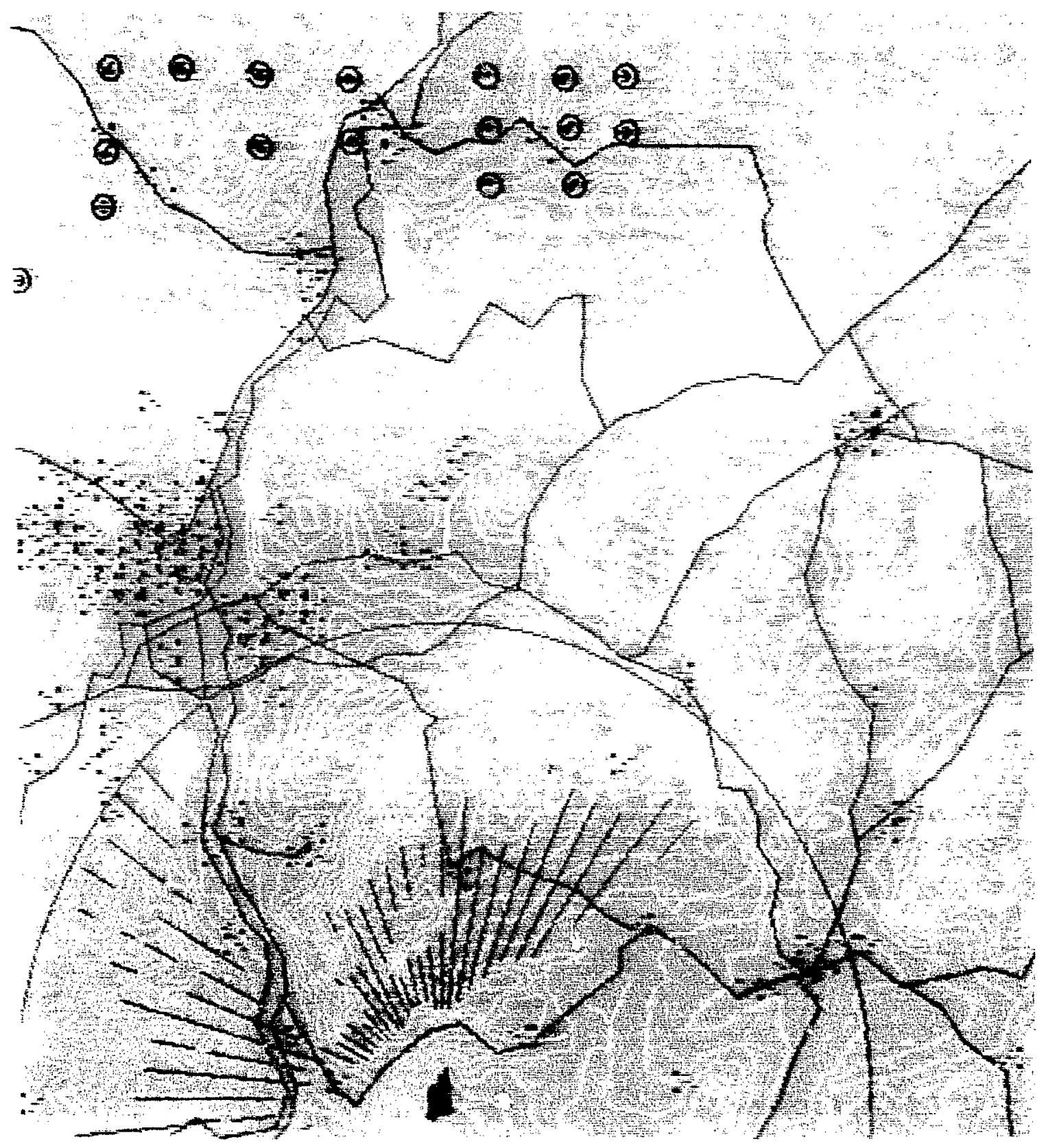

Figure C4. Typical line-of-sight fan showing line of sight for location B. 


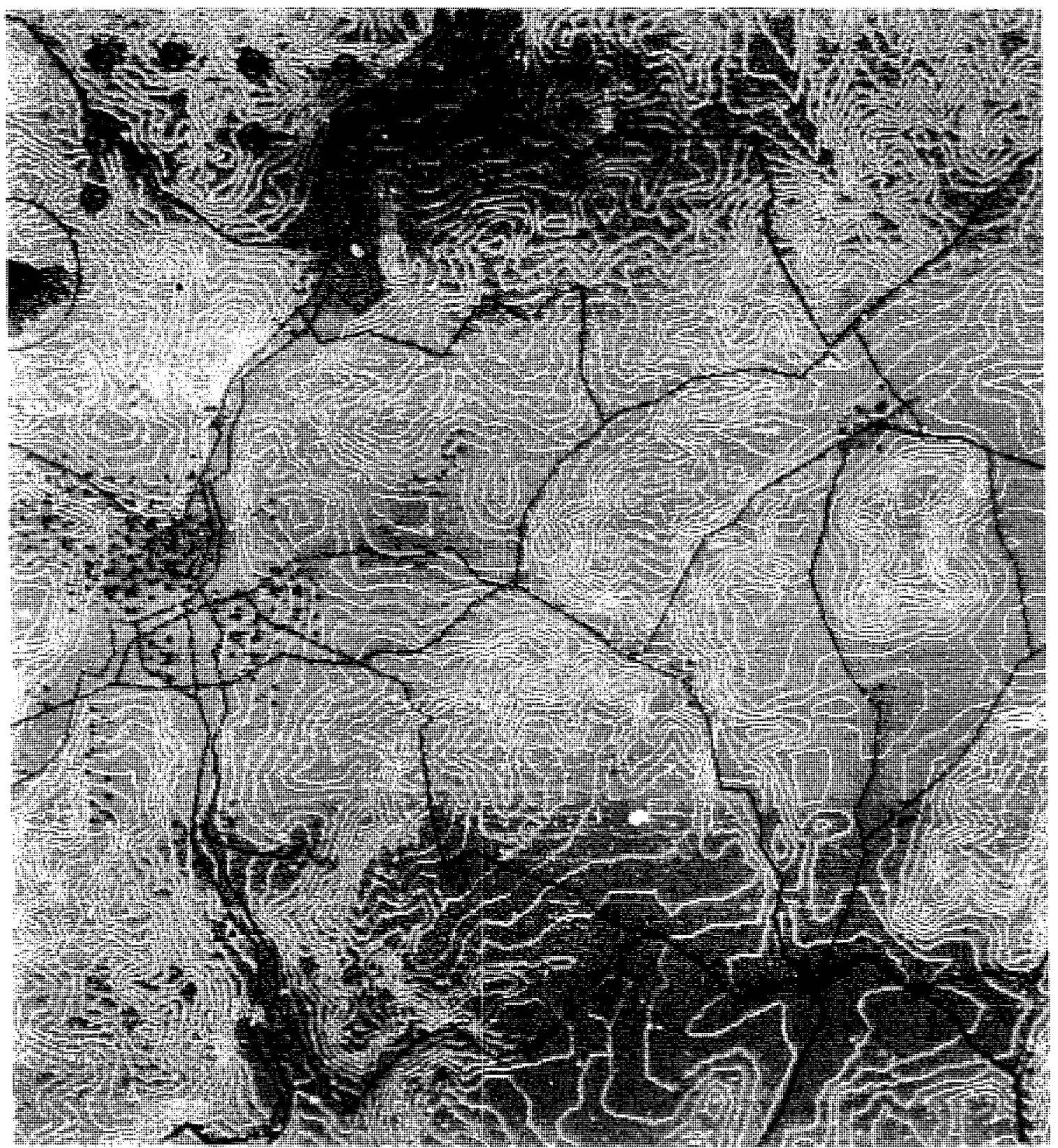

Figure C5. Typical line-of-sight fan showing location C. 


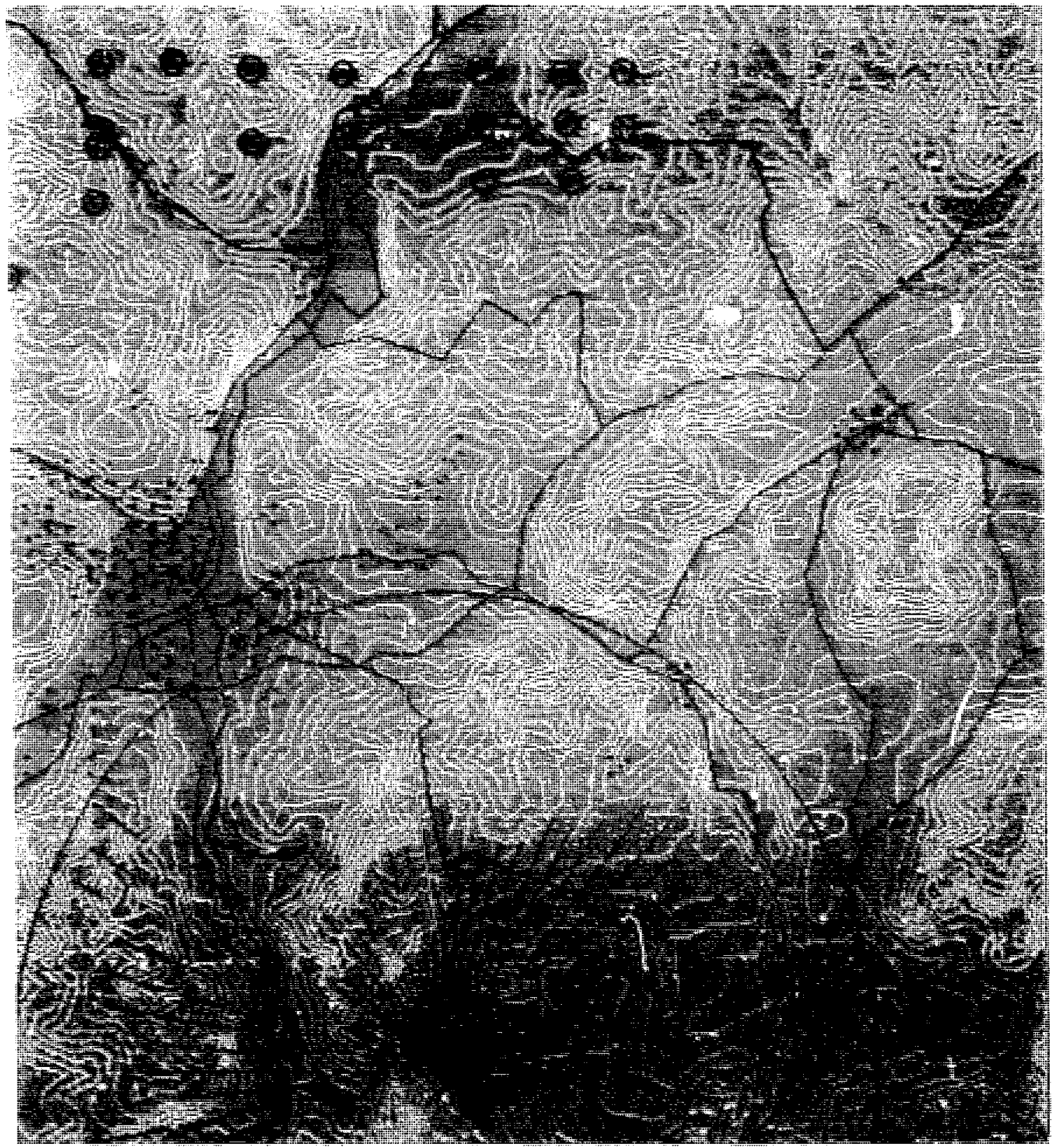

Figure C6. Typical line-of-sight fan showing line of sight for location C. 


\section{Appendix D. JANUS Operations for this Study}

JANUS went through considerable updating during the course of this study: new and more accurate parameters were introduced and errors were corrected. There were few modifications to its past structure per se. A line-of-sight fan with a range circle indicating the range of direct-fire weapons was developed for each unit to facilitate the player's understanding of the contour lines on the screen. (As an example, it facilitated differentiating peaks and holes. It also proved valuable in identifying military crests.) The effects parameters were set to model the Army damage criteria. The forward observers were modified so that they would not be immune to kill while at rest.

Off-road velocities were incorrectly modcled for the first major portion of the study. This made a significant difference in the relationship between simulation time and troop movement during an offensive attack, and also affected the timely achievement of a battle objective, an important aspect of Red doctrine. Correctly modeling off-road velocities nct only changed the timely achievement of a battle objective but also made temporarily incapacitating nuclear exposures less important to the general progress of a battle. (More troops returned to fight before the end of the battle as the simulation clock time was increased. Earlier in the game, before the simulation clock time was changed, fewer troops returned to fight.)

Achieving mcre than one simulation per day was extremely difficult. If two experienced players used initial positions inherited from an earlier exercise, sometimes two games could be played. Since we could not store all aspects of a game in progress onto a disk, we could not continue an uncompleted game the following day. 


\section{Appendix E. Can a Simulation Code Tell Who Wins?}

Using a simulation code to answer a specific question is difficult. For example, with JANUS, the frequently asked question "who won the game?" carries the assumption that a change in a specific parameter or a specific yield will have a major effect on the outcome of the game. The truth is that a multitude of other factors could change the course of the game as well. Thus, running a simulation code is not the same as running a Monte Carlo computer code, where, by using different random number seeds and repeating runs, we reduce tha probability of uncertainty in the results. In any one grame, the outcome of a simulation code is the end product of a large number of rather arbitrary decisions about what to do with the physical characteristics of the units involved and how best to do it. Hughes*:

When using simulations or studies, then, one should remember the following four points made by

1. Defense simulations or studies are limited by the uncertainties inherent in war.

2. Because of these uncertainties, a simulation or a study cannot predict the outcome of a war; it can, however, advise us on preparing for war.

3. If we recognize these uncertainties, we will produce more valuable studies and more effective simulations and will be able to give better advice on war strategies.

4. If we neglect these uncertainties, there will be unpleasant consequences.

We should also remember that one becomes a wiser analyst with a better understanding of interrelated problems when ho uses a complex model in many different battle simulations, against many different opponents. 